\title{
EXPERIENNCIA TRANSICIONAL DE ENFERMEIROS EM UM PROGRAMA DE RESIDÊNCIA
}

\author{
TRANSITIONAL EXPERIENCE OF NURSES \\ IN A RESIDENCY PROGRAM
}

\section{EXPERIENCIA DE TRANSICIÓN DE ENFERMERAS EN UN PROGRAMA DE RESIDENCIA}

\author{
Rosana Maria de Oliveira Silva ${ }^{1}$ \\ Josicelia Dumêt Fernandes ${ }^{2}$ \\ Maria Deolinda Antunes da Luz ${ }^{3}$ \\ Gilberto Tadeu Reis da Silva ${ }^{4}$ \\ Ana Lúcia Arcanjo Oliveira Cordeiro 5 \\ Giselle Alves da Silva Teixeira ${ }^{6}$
}

Como citar este artigo: Silva RMO, Fernandes JD, Luz MDA, Silva GTR, Cordeiro ALAO, Teixeira GAS. Experiência transicional de enfermeiros em um programa de residência. Rev baiana enferm. 2019;33:e34564.

Objetivo: analisar as condições vivenciadas por enfermeiros durante a experiência transicional em um programa de residência. Método: estudo exploratório, qualitativo, que utilizou a história oral de vida temática, fundamentada na teoria de transição de Afaf Meleis. Participaram do estudo 40 enfermeiros egressos de um curso de residência, cujas narrativas foram submetidas à análise de conteúdo temática. Resultados: foram experienciadas condições favoráveis e desfavoráveis que expressaram a coesão entre a instituição de ensino e os cenários de prática, a integração das equipes gestora e executora, a coerência do conteúdo teórico e prático, o apoio da rede social, o conhecimento de pessoas e o estabelecimento de laços de amizade, a queda do padrão de vida, o acúmulo de atividades e o afastamento de vínculos sociais. Conclusão: o significado e o valor atribuídos pelos egressos às condições favoráveis e desfavoráveis vivenciadas durante a experiência transicional em um programa de residência interferiram na adaptação, no desenvolvimento da transição e nos resultados da experiência transicional.

Descritores: Educação de Pós-Graduação em Enfermagem. Internato não Médico. Especialização. Enfermagem.

Objective: to analyze the conditions experienced by nurses during the transitional experience in a residency program. Method: qualitative, exploratory study, which used oral history of life theme, based on the theory of transition of Afaf Meleis. The participants were 40 nurses graduated from a residency course, whose narratives were submitted to thematic content analysis. Results: they experienced favorable and unfavorable conditions that expressed the cohesion between the educational institution and practical scenarios, the integration of the managing and executing teams, the consistency of the theoretical and practical content, support from the social network, people's knowledge and the establishment of friendship bonds, the decreased standard of living, the accumulation of activities and the distancing from social bonds. Conclusion: the meaning and the value attributed by the students to favorable and

\footnotetext{
Enfermeira. Doutora em Enfermagem. Professora da Universidade Federal da Bahia. Salvador, Bahia, Brasil. rosanaosilva@hotmail.com. https://orcid.org/0000-0003$337 \mid-6550$.

Enfermeira. Doutora em Enfermagem. Professora da Universidade Federal da Bahia. Salvador, Bahia, Brasil. https://orcid.org/0000-0003-2946-53।4.

Enfermeira. Doutora em Enfermagem. Professora da Escola Superior de Enfermagem de Lisboa. Lisboa, Portugal. https://orcid.org/0000-0003-0662-0609.

Enfermeiro. Doutor em Enfermagem. Professor da Universidade Federal da Bahia. Salvador, Bahia, Brasil. https://orcid.org/0000-0002-0595-0780.

Enfermeira. Doutora em Enfermagem. Professora da Universidade Federal da Bahia. Salvador, Bahia, Brasil. https://orcid.org/0000-0002-0375-7709.

Enfermeira. Doutora em Enfermagem. Professora da Universidade Federal da Bahia. Salvador, Bahia, Brasil. https://orcid.org/0000-000 I-6245-302X
} 
unfavorable conditions experienced during the transitional experience in a residency program interfered in the adaptation, the development of the transition and in the results of the transitional experience.

Descriptors: Education, Nursing, Graduate. Internship, Nonmedical. Specialization. Nursing.

Objetivo: analizar las condiciones experimentadas por las enfermeras durante la experiencia de transición en un programa de residencia. Método: estudio cualitativo, exploratorio, que utilizó la historia oral de vida temática, basada en la teoría de la transición de Afaf Meleis. Participaron en este estudio 40 enfermeras graduadas del curso de residencia, cuyas narrativas fueron sometidas al análisis de contenido temático. Resultados: fueron experimentadas condiciones favorables y desfavorables que expresan la cohesión entre la institución de enseñanza y escenarios de práctica, la integración de los equipos gestor y ejecutor, la coherencia de los contenidos teóricos y prácticos, el apoyo de la red social, el conocimiento de las personas y el establecimiento de lazos de amistad, la caída del nivel de vida, la acumulación de actividades y la ruptura de los lazos sociales. Conclusión: el significado y el valor atribuido por los estudiantes a condiciones favorables y desfavorables que experimentaron durante la experiencia de transición en un programa de residencia interferón en la adaptación, el desarrollo de la transición y los resultados de la experiencia de transición.

Descriptores: Educación de Postgrado en Enfermería. Internado no Médico. Especialización. Enfermería.

\section{Introdução}

A experiência transicional é compreendida como resultado de mudanças e determinantes de transformação na vida, na saúde, nos relacionamentos e nos ambientes nos quais o indivíduo está inserido ${ }^{(1)}$.

Fundamentado na teoria de transição de médio alcance de Afaf Meleis ${ }^{(1)}$, o processo de transição que ocorre na vida do indivíduo pode ser proveniente de uma mudança ou causador de uma mudança. Isso quer dizer que o processo de transição é a passagem ou o movimento de um estado para outro ou de uma condição para outra. Entretanto, para que seja deflagrada, é necessário um evento ou um marco gerador do processo.

A teoria descreve a existência de quatro tipos de transição: desenvolvimental, saúde-doença, organizacional e situacional ${ }^{(1)}$. A transição desenvolvimental foi identificada nos trabalhos de enfermagem que abordam estágios do ciclo de vida que focaram, em sua maioria, o indivíduo. Podem-se citar como exemplos a adolescência, a menopausa e a senilidade ${ }^{(2)}$. A transição saúde-doença relaciona-se com acontecimentos que originam alterações de papéis ${ }^{(2)}$. A transição organizacional, como mudanças no ambiente social, político, econômico ou mudanças na estrutura ou na dinâmica organizacional, ocorre nas organizações e interfere na vida dos trabalhadores e na de seus clientes. A transição situacional foi identificada com um percentual significativo de trabalhos voltados às situações na área educacional da enfermagem, com os seguintes temas: transição na preparação educacional na enfermagem; transição e seus significados na perspectiva dos níveis de conhecimento de estudantes de enfermagem; e transição dentro e ao longo de programas educacionais ${ }^{(2)}$.

Nesse sentido, o processo de qualificação do enfermeiro, por meio de um programa de residência, possibilita mudanças, no âmbito profissional, de seu nível de conhecimento, hábitos, culturas, atitudes, comportamentos e valores éticos e morais, com consequente reconstrução de sua identidade profissional.

Diante do exposto, o marco gerador da experiência transicional neste estudo foi a realização do curso de residência em enfermagem.

Como subsídio teórico, para melhor conhecimento sobre o tema abordado, privilegiou-se a teoria de transição de médio alcance de Afaf Meleis, especificamente no que tange à transição situacional, uma vez que aborda a transição que ocorre dentro e ao longo de programas educacionais. Essa é entendida como mudança na vida de uma pessoa ao experienciar determinadas situações ${ }^{(1,3)}$.

Em virtude do rito de passagem e das consequências que podem advir de uma transição acadêmica e de vida, é importante identificar as 
condições vivenciadas, o processo de adaptação, a aprendizagem e o desenvolvimento oriundos dela, pois estes influenciam na evolução e nos resultados da experiência transicional ${ }^{(1,4)}$. Dessa forma, este estudo pode fornecer subsídios que possibilitem desenvolver ajustes na formação dos discentes, frente às necessidades de saúde da população e na promoção do marketing institucional.

Tendo em vista que ocorreram mudanças na trajetória pessoal e profissional dos egressos, foi levantada a seguinte questão: Quais as condições vivenciadas por enfermeiros durante a experiência transicional ocorrida em um programa de residência?

Este estudo tem como objetivo analisar as condições vivenciadas por enfermeiros durante a experiência transicional ocorrida em um programa de residência.

\section{Método}

Estudo exploratório com abordagem qualitativa, cujo método utilizado foi a história oral de vida temática, fundamentado na teoria de transição de médio alcance de Afaf Meleis, que enfatiza a importância do conceito e do processo de transição, e as implicações para a prática da enfermagem na promoção, na prevenção e nas intervenções na saúde. Contribui também para o aumento do conhecimento específico da ciência da enfermagem ${ }^{(3)}$.

Foram incluídos nesta pesquisa egressos que residiam no estado da Bahia e realizaram o curso de especialização sob a forma de residência nas áreas da especialidade Enfermagem em Unidade de Terapia Intensiva e Enfermagem em Bloco Cirúrgico, de uma instituição de ensino da rede pública da Bahia, certificados no período compreendido entre 1996 e 2009.

Buscou-se a identificação e a localização dos egressos nos registros da Secretaria da Pós-Graduação da instituição de ensino, porém os endereços e contatos estavam desatualizados. Diante dessa situação, a busca foi reiniciada por meio da técnica chamada snowball sampling (bola-de-neve), utilizada para encontrar sujeitos da pesquisa que são desconhecidos ou ocultos. Consiste na indicação, pelos primeiros sujeitos, de outros, que indicam outros, e assim sucessivamente ${ }^{(5)}$.

A coleta de dados ocorreu por meio de entrevistas semiestruturadas, no período de janeiro a março de 2012, em locais previamente escolhidos pelos participantes, apenas com a participação do pesquisador e do entrevistado. Participaram da pesquisa 40 enfermeiros egressos do curso de especialização sob a forma de residência.

Foi entregue aos participantes uma carta-convite e, no momento inicial da entrevista, foram explicitados os objetivos e as possíveis repercussões do processo investigativo. Foram garantidos aos participantes o anonimato e a omissão do local da entrevista. Os participantes receberam e assinaram o Termo de Consentimento Livre e Esclarecido (TCLE) em duas vias, ficando com uma via, e a outra foi devolvida ao pesquisador. Após a aquiescência do participante, procedeu-se à gravação do registro oral, por meio de gravador digital. Cada entrevista teve duração média de 90 minutos.

Foram efetuadas 94 horas e 42 minutos de transcrição. Nessa etapa, foi utilizado o software profissional Express Scribe 5.20, para controle de playback de áudio, e consideraram-se as etapas ${ }^{(6)}$ transcrição absoluta, textualização e conferência pelos participantes. Tendo em vista a existência de diferenças entre o que foi narrado e o que foi escrito, foi necessário que o participante lesse o que foi transcrito e autorizasse sua utilização.

As narrativas foram submetidas à análise de conteúdo temático, que permite fazer inferências sobre informações encontradas no contexto no qual estão inseridas e possibilita que a análise ultrapasse o caráter meramente descritivo e alcance o caráter analítico. A investigação seguiu as três etapas da análise de conteúdo: pré-análise, exploração do material e tratamento dos resultados - a inferência e a interpretação ${ }^{(7)}$.

$\mathrm{Na}$ pré-análise, o material proveniente das entrevistas foi organizado. Posteriormente, realizou-se a leitura flutuante. Na segunda etapa, de exploração do material, foram feitas releituras de todo o conteúdo do corpus da pesquisa, iniciando com a identificação e a apreensão das unidades de contexto - frases, isto é, parágrafos 
do corpus que representavam as condições favoráveis e desfavoráveis da experiência transicional na trajetória dos egressos do curso. A terceira e última etapa, que consistiu na inferência e na interpretação, foi realizada mediante a interpretação dos resultados, considerando o referencial da teoria de transição de Afaf Meleis ${ }^{(1)}$.

Para preservar a identidade dos egressos, optou-se pela utilização do sistema alfanumérico, por meio do codinome $\mathrm{P}$, relativo ao participante, seguido da numeração arábica, conforme a ordem de ocorrência das entrevistas (P1, P2, P3... P40).

$\mathrm{O}$ estudo foi realizado atendendo à Resolução n. 466, 12 de dezembro de 2012, do Conselho Nacional de Saúde, que dispõe sobre as diretrizes e normas regulamentadoras de pesquisas envolvendo seres humanos. O projeto foi aprovado pelo Comitê de Ética e Pesquisa da instituição onde o estudo foi realizado, sob Parecer n. 35/2010.

\section{Resultados}

A análise das entrevistas possibilitou a construção de duas categorias: condições favoráveis e condições desfavoráveis.

\section{Condições favoráveis}

As condições favoráveis da experiência transicional vivida pelos participantes deste estudo e ilustrada com suas citações, foram: coesão entre a Instituição de Ensino Superior (IES) e os cenários de prática, evidenciada pela metodologia utilizada nas salas de aula pelo professor; integração entre as equipes gestora e executora do Curso; coerência entre o conteúdo teórico e o prático; apoio da rede social; conhecimento de pessoas e estabelecimento de laços de amizade.

A coesão instituição de ensino superior-cenários de prática pôde ser evidenciada pela metodologia utilizada nas salas de aula pelo professor.

\footnotetext{
Na sala de aula, a gente discutia muito as questões. Tanto as questões burocráticas quanto as questões da prática mesmo. Então, a gente via na prática, nos campos da residência, acontecer uma situação, a gente levava pra sala de aula, e isso era discutido com a professora. E aí ela ia norteando a gente como deveria ser nossa postura, qual seria o correto, o que a literatura traz em relação a isso [...] (P23).
}

[...] a gente vinha pras aulas teóricas e eram excelentes, onde a gente podia implementar na prática; quando a gente voltava para o paciente, a gente se lembrava de tudo que a gente pôs aqui na teoria [...] (P4).

[...] durante a residência, você tem as aulas teóricas, que você apresenta diariamente [...] então isso facilita [...] é obrigado você estudar [...] (P17).

A integração da equipe gestora e executora do curso foi de grande relevância, para que um curso, sob a forma de residência, assegurasse a consecução de seus objetivos, que houvesse a integração entre as equipes gestora e executora do curso, professor, coordenador, preceptores e a equipe multiprofissional do serviço, partindo do pressuposto que o projeto era fruto de uma parceria entre a instituição de ensino superior e a organização hospitalar. Esse fato foi percebido e relacionado pelo egresso como favorecedor ao desenvolvimento do curso:

[...] eu sentia de forma mais presente a figura do coorde-
nador de unidade de terapia intensiva e do professor, o
docente responsável pela residência. A equipe de enferma-
gem era mais coesa, mais unânime, caminhava de uma
forma mais harmônica e o estudante, ele percebia esse rit-
mo, ele acabava se adequando a esse ritmo [...] (P5).

Outro aspecto relatado pelos egressos, evidenciando a coesão entre a teoria e a prática, foi a coerência entre o conteúdo teórico e prático. Conforme ilustram as falas a seguir:

A gente tá vendo aquilo que a gente discute na sala com a prática [...] (P23).

[...] são muitas discussões que giram em torno das atividades que a gente desenvolve. Não é só questão da prática. A residência que eu fiz, ela atrela a teoria e a prática simultaneamente. Você está o tempo inteiro tendo aula e o tempo inteiro a prática. Tudo que você está estudando, você está vivenciando, tá colocando ali na prática [...] (P2).

Se dedicar, estudar, buscar. Ir pra prática tentando sempre encontrar o que tem na teoria. Então, isso dá uma segurança, um conbecimento muito grande pra gente [...] (P33).

Outra condição que favoreceu a experiência transicional, referida pelos egressos, foi o apoio da rede social, representada pelos pais, professores e preceptores:

Eu tive um apoio muito grande dos meus pais em termos financeiros, em termos emocionais [...] muitas vezes eu liguei chorando pro interior. Meus pais, diziam "se você quiser venha hoje, mas amanhã você volta!" [Riso] minha mãe sempre dizia isso, não chore, não chore porque você é forte [...] (P4).

[...] meus avós paternos foram meus maiores incentivadores, foram as pessoas que "Não. Você tem que sair do interior e ir pra capital estudar!", e assim meu avô foi 
a pessoa mais fundamental assim, motivadora pra mim, "vá lá, ache um emprego e não se preocupe o que você precisar, você vai ganhar essa bolsa da residência, é uma bolsa minima, não vai dar pra tudo, mas o que você precisar a gente tá aqui”, então, assim, ele foi meu maior incentivador [...] (P7).

Face ao conhecimento de pessoas e a criação de laços de amizade, o convívio diário, durante todo o curso, entre residente, preceptor e professor favoreceu a aproximação e o conhecimento entre eles, sendo factível a possibilidade de que se ajudassem no desenvolvimento pessoal e profissional, conforme relatado:

O conbecimento de pessoas e a formação de laços de amizade durante a realização do curso foram mencionados como favorecedores da experiência transicional: "é um laço de amizade que a gente faz, enquanto a gente tá naquele momento da residência [...] eu sempre me senti acolbida dentro da UTI [...] (P8).

As amizades aumentaram, porque você está num ambiente maior. Eu vim morar aqui em Salvador [...] (P22).

Fortalecimento também das pessoas que já se conbeciam e do grupo como um todo. Então, isso foi muito importante [...] Favoreceu o fortalecimento [...] o conbecimento das pessoas que não se conbeciam [...] (P1).

\section{Condições desfavoráveis}

Nesta categoria, foram referidas três situações que estiveram intimamente relacionadas: queda do padrão de vida, acúmulo de atividades e afastamento de vínculos sociais.

A queda do padrão de vida foi relatada pela enfermeira como condição desfavorável vivenciada por ela durante a experiência transicional:

\footnotetext{
Uma das maiores mudanças foi a questão do padrão de vida nesse periodo. Eu tive que abdicar de muitas coisas que, enquanto estudante, eu não tinha, que eu tinha adquirido em um ano ter direito a carro, a passeios e tal, pra poder fazer a residência [...] (P6).

[...] os problemas eram mais assim o stress mesmo, falta de tempo, de saudade de casa, de falta de dinheiro [Riso] que a bolsa era quatrocentos reais [...] (P4).
}

Quanto ao acúmulo de atividades, os egressos referiram sentir-se sobrecarregados pelo acúmulo das diversas atividades desenvolvidas no curso:

[...] realizar o curso foi bastante puxado. Foi um ano que precisei trabalhar a noite [...] (P3).

[...] tinha que trabalhar e estudar. Então, as coisas fora da residência ficaram um pouco prejudicadas no momento, mas eu sabia que esse era o momento de priorizar a formação [...] (P1).
Devido ao afastamento dos vínculos sociais, segundo os relatos, os enfermeiros, por necessidade de se dedicarem ao curso, em função dos diversos compromissos e responsabilidades assumidos, precisaram afastar-se de seus familiares e de seu contexto social, e passaram a constituir novos vínculos com pessoas que faziam parte de seu novo meio social, pela proximidade existente entre eles.

Eu vim, larguei... meu referencial de familia, referencial de vida até então. Eu tinha na época 24 anos [riso]. Eu larguei tudo, larguei família e vim [...] (P4).

[...] a vivência fora do ambiente, da academia, dos hospitais de formação durante esse período ficou um pouco prejudicado por causa do tempo [...] (P1).

\section{Discussão}

A coesão instituição de ensino superior-cenários de prática, revelada e valorizada pelos egressos, foi um aspecto favorecedor da transição e traduziu a importância do diálogo entre as situações que ocorrem na prática e a teoria associada na academia, como metodologia que permite o desenvolvimento professor/aluno no contexto do processo formativo. Desse modo, o professor não atua como transmissor de saberes, mas na problematização do saber emanado da prática, por meio da crítica e da reflexão dialógica. Seguindo essa linha de raciocínio, o professor, por seu preparo, tem a função, no processo formativo, de "ligar e religar saberes" ${ }^{(8)}$.

Essa metodologia exige do professor uma reflexão sobre seu cotidiano, o mundo e a enfermagem, como forma de repensar o refazer e o recriar do modo de cuidar e dos cuidados prestados, uma vez que o cuidado não está delimitado a uma ação pontual, mas abrange diferentes dimensões ${ }^{(9)}$.

A lógica de uma formação contextualizada, problematizada, com conteúdos programáticos flexíveis possibilita posicionar o aluno como sujeito de sua aprendizagem, que critica e reflete, na medida em que permite a consolidação do conhecimento oriundo de sua atuação profissional. $\mathrm{O}$ ato de aprender não se resume em passagem de informações, mas envolve complexas interações entre o aluno e o professor, o ambiente e os objetos ${ }^{(10)}$. 
A formação por meio de um curso de residência é processual, integrativa e tem como fundamento o saber adquirido pela experiência ${ }^{(11)}$.

Os enfermeiros perceberam a articulação existente entre os componentes da instituição de ensino superior e a organização hospitalar, e isso foi essencial para que percebessem que a responsabilidade por sua formação faz parte de um projeto comum entre as duas organizações, tornando o residente sujeito comprometido com sua formação.

Nesse sentido, o comprometimento é entendido como o grau de envolvimento demonstrado pelo indivíduo com a experiência transicional. No entanto, o indivíduo só se compromete se tiver consciência da transição que vivencia ${ }^{(1)}$.

Em virtude de as transições serem processuais e ocorrerem ao longo do tempo, é importante perceber os indicadores de processo. São eles: sentir-se conectado, referir relações antigas ou recentes e integração. Por meio da interação, é possível conhecer o significado da transição, e descobrir e esclarecer os comportamentos advindos dela, a localização e a orientação no tempo, no espaço e nas relações, que indicam se a pessoa está se direcionando a uma transição saudável ${ }^{(2-3)}$.

Foi possível perceber os indicadores do processo de transição durante as falas dos participantes, que demonstraram a integração entre equipes gestora e executora. A percepção da harmonia entre os membros que compõem a residência favorece a adaptação dos residentes ao formato do curso e a transição em seu modo de ser, pensar, agir, fazer e se relacionar.

Dessa maneira, esse curso envolve um tecido social que objetiva construir/reconstruir valores, habilidades técnicas e relacionais, e condutas éticas, para que o indivíduo desenvolva um modo de ser pessoal e profissional. Admite-se que, nesse contexto, se encerram parcerias relevantes ao processo de socialização do indivíduo, como o cerne da aprendizagem individual e organizacional.

Os relatos evidenciaram que o curso de residência possibilitou ao enfermeiro refletir sobre o saber e o saber fazer em seu processo de aprendizagem, o que minimizou a tensão e o desânimo causados pela dicotomia entre a teoria e a prática, tão presentes nos processos formativos. É relevante afirmar que a formação do especialista fundamenta-se na coerência entre a teoria e a prática ${ }^{(12)}$. O conhecimento científico permite a construção de hipóteses, e a prática permite a apreensão da realidade. Ambos são de igual importância para a formação do profissional.

Desse modo, só é possível considerar como conhecimento profissional aquele que resulta da associação entre o conhecimento adquirido no contexto da prática e o conhecimento teórico, previamente produzido ou conhecido no contexto profissional. Não se trata de conceber uma teoria que se aplica na prática, mas de uma prática que pode ser antecipada, observada e analisada em um quadro teórico a ser desenvolvido ou modificado por meio dela ${ }^{(13)}$.

O suporte social, exemplo de condição de transição, é definido como circunstâncias que podem facilitar ou inibir o alcance de uma transição saudável e dependem da percepção do indivíduo e do significado que ele atribui a essa experiência $^{(2)}$. Neste estudo, pôde-se identificar o apoio da rede social, compreendido como o conjunto de todas as relações significativas para o indivíduo ${ }^{(14)}$; tem-se, desse modo, as relações familiares, de trabalho e acadêmicas. O apoio da rede social pode ser de ordem emocional, financeira ou informacional, oferecido e percebido pelas pessoas que constituem a rede.

A adesão de familiares ao projeto do profissional de se especializar, manifestada por meio do apoio nas diferentes ordens, funcionou como alicerce para o alcance dos objetivos, principalmente para aqueles que não possuíam renda própria e aos que precisaram sair do seio de sua família, por conta do curso ser ofertado em outra cidade. O apoio da família é fundamental para a manutenção do equilíbrio e adaptação do indivíduo durante uma experiência transicional, tendo em vista que a colaboração no trabalho, a comunicação efetiva e o suporte social contribuem para a criação de condições propícias à transição ${ }^{(3)}$. Pode-se considerar o apoio oferecido pelos familiares aos residentes, como 
emocional e instrumental. Emocional porque contribuiu para que eles se sentissem apoiados, amados e cuidados, elevando a autoestima com os incentivos recebidos; instrumental porque se deu pela ajuda financeira, concreta ${ }^{(15)}$.

Com relação ao apoio oferecido pelo professor ou pelo preceptor, revelado pelas falas, é válido ressaltar que o docente, por sua capacitação técnica para o ensino, deve estar preparado para ponderar as necessidades individuais do discente no processo de ensino-aprendizagem ${ }^{(8)}$. Ainda, deve entender que o residente, em sua singularidade, em determinados momentos desse percurso, convive com problemas que refletem em seu comportamento e aprendizado de forma positiva ou negativa. Desse modo, é necessário sentir-se apoiado no decorrer do curso, para que existam condições de superar desafios causados por problemas e fragilidades de ordem pessoal e profissional.

Esse tipo de apoio social é chamado de informacional, por se tratar de uma ajuda por meio de informações, conselhos e opiniões. Entende-se que os efeitos traumáticos de uma experiência transicional são minimizados ${ }^{(15)}$.

O apoio de familiares, amigos e parceiros é essencial para quem vivencia uma transição, principalmente nas transições profissionais, pois, quando esse apoio não ocorre, há predisposição a sentimentos de frustração, impotência, dúvidas, dentre outros ${ }^{(3)}$.

A dinâmica intensiva da residência, em contextos reais de trabalho, em que a prestação dos serviços fundamenta-se na interdisciplinaridade, congregando um número elevado de profissionais a trabalharem diariamente muito próximos, faz com que todos se identifiquem, formem laços de amizades e promovam o desenvolvimento da competência relacional.

O meio social do residente passa a ser o contexto do curso, isto é, a instituição de ensino superior e/ou as organizações hospitalares, por conta da exclusividade exigida e da gama de atividades a serem desenvolvidas. A integração entre as pessoas que fazem parte do ambiente no qual ocorre a transição evita o isolamento social dessas pessoas ${ }^{(3)}$. Essa interação é considerada um padrão de resposta, que é a forma como as pessoas respondem à transição e engloba indicadores como a criação de laços de amizade, o que caracteriza uma transição saudável ${ }^{(1)}$.

É fato que, quando o processo de ensino-aprendizagem ocorre num ambiente amistoso, há uma tendência de o residente sentir-se acolhido e incluído no contexto de formação, o que facilita sua transição. A enfermagem é uma das profissões que tem como base o trabalho de interação, aquele que se desenvolve com o outro e para os outros, sendo necessário, para seu bom desempenho, investir nos recursos cognitivos e afetivos das relações ${ }^{(16)}$.

O bem-estar emocional é compreendido como indicador de uma experiência transicional saudável, pois, durante a transição, pode surgir uma gama de sentimentos, como conflito de papéis, baixa autoestima, medo de fracassar e sentimento de sobrecarga, que são geridos apropriadamente pelo indivíduo se ele sentir-se apoiado. Assim, credita-se ao bem-estar nos relacionamentos o indicativo de uma transição que obteve êxito ${ }^{(3)}$.

O indivíduo em transição, ao entender sua nova condição, por meio da comparação com a anterior, situa-se no tempo, no espaço e na relação com o outro ${ }^{(1)}$. Isso pode ser observado no relato em que o participante referiu ter que "abdicar de muitas coisas", pois tinha a consciência da condição em que se encontrava e não mais poderia proceder como antes.

A conscientização está relacionada à percepção, ao conhecimento e ao reconhecimento de uma experiência transicional pelo indivíduo. A conscientização é condição sem a qual não aconteceria uma transição, isto é, todo indivíduo deve estar consciente do processo que vivencia e das consequências para si e para o contexto do qual faz parte. Numa transição, é suposto existir algum grau de consciencialização das mudanças que ocorrem. O nível de consciencialização influencia no grau de envolvimento, pois a pessoa só pode envolver-se depois de ter noção da $\operatorname{mudança~}^{(1,3)}$.

A residência tem a figura do residente como sujeito de sua aprendizagem. A maioria das 
atividades é planejada e elaborada por ele, exigindo dedicação de tempo integral ao curso. Essa forma de se adaptar à situação vivenciada causa cansaço, desgaste físico e emocional, prejudicando o desenvolvimento da transição.

Segundo os relatos, os enfermeiros, por necessidade de se dedicarem ao curso, em função dos compromissos e das responsabilidades assumidas, precisaram afastar-se de seus familiares e do contexto social fora do círculo do curso, e passaram a constituir novos vínculos com pessoas que faziam parte de seu novo meio social, pela proximidade existente entre eles. Entende-se que o afastamento desses vínculos é uma das características do processo transicional ${ }^{(1)}$.

\section{Conclusão}

As condições vivenciadas por enfermeiros egressos de um programa de residência durante a experiência transicional englobam condições favoráveis e desfavoráveis. As condições favoráveis evidenciadas foram: coesão entre a instituição de ensino superior e os cenários de prática; integração da equipe gestora e executora do curso; articulação e coerência entre o conteúdo teórico e prático; apoio da rede social; conhecimento de pessoas e criação de laços de amizade. As condições desfavoráveis foram: queda do padrão de vida, acúmulo de atividades, e afastamento de vínculos sociais.

No entanto, compreendendo que o significado e o valor atribuídos pelos egressos às condições favoráveis e desfavoráveis interferiram na adaptação, no desenvolvimento da transição e nos resultados esperados da experiência transicional, fica reconhecida a importância da análise dessas condições ao longo do processo de transição.

O estudo fornece subsídios que possibilitam que se desenvolvam estratégias que facilitem o processo de transição vivenciado por enfermeiros em um curso de residência.

\section{Colaborações:}

1 - concepção, projeto, análise e interpretação dos dados: Rosana Maria de Oliveira Silva,
Ana Lucia Arcanjo Oliveira Cordeiro, Josicelia Dumêt Fernandes e Maria Deolinda Antunes da Luz;

2 - redação do artigo e revisão crítica relevante do conteúdo intelectual: Gilberto Tadeu Reis da Silva e Giselle Alves Teixeira.

3 - aprovação final da versão a ser publicada: Rosana Maria de Oliveira Silva.

\section{Referências}

1. Meleis AI, Sawyer LM, Im E, Messias DK, Shumacher K. Transitions theory. In: Meleis AI, editor. Transitions theory: middle-range and situation-specific theories in nursing research and practice. New York: Springer Publishing Company; 2010. p. 52-64.

2. Silva RMO, Fernandes JD, Luz MDA, Cordeiro ALAO, Silva LS, Silva ACP. Concepción de la teoría de transición de Afaf Meleis. Posibilidades de aplicación para la enfermería. Rev ROL enferm. 2017;40(7-8):498-503.

3. Schumacher KL, Meleis AI. Transitions: a central concept in nursing. In: Meleis AI, editor. Transitions theory: middle-range and situationspecific theories in nursing research and practice. New York: Springer Publishing Company; 2010. p. 38-51.

4. Siares AB, Francischetto V, Dutra BM, Miranda JM, Nogueira CC, Leme VR, et al. The impact of expectations on the students' academic adaptation in Higher Education. Psico-USF. 2012;19(1):49-60. DOI: http://dx.doi.org/10.1590/ S1413-82712014000100006

5. Vinuto J. A amostragem em bola de neve na pesquisa qualitativa: um debate em aberto. Temáticas [Internet]. 2014 [cited 2019 Nov 29];22(44):203-20. Available from: https://pdfs.semanticscholar.org/ cd8e/3ecb215bf9ea6468624149a343f8a1fa8456. pdf?_ga $=2.29421183 .1507629889 .1575297791$ 1765719457.1575297791

6. Ribeiro MC, Machado AL. O uso do método história oral nas pesquisas qualitativas: contribuições para a temática do cuidado em saúde mental. Estudos pesqui psicol [Internet]. 2014 [cited 2019 Nov 29];14(2):578-91. Available from: https://www.epublicacoes.uerj.br/index.php/revispsi/article/ view/12562/9861

7. Bardin L. Análise de Conteúdo. 5a ed. Lisboa: Edições 70; 2011. 
8. Backes DS, Marinho M, Costenaro RS, Nunes S, Rupolo I. Rethinking the to be a nurse teacher in the perspective of the complex thought. Rev bras enferm. 2010;63(3):421-6. DOI: http://dx.doi. org/10.1590/S0034-71672010000300012

9. Backes DS, Backes MS, Dalcin CB, Erdmann AL. The nursing care system from a Luhmannian perspective. Rev Latino-Am Enfermagem. 2012;20(5):873-9. DOI: http://dx.doi.org/10.1590/ S0104-11692012000500008

10. Mello CCB, Alves RO, Lemos SMA. Metodologias de ensino e formação na área da saúde: revisão de literatura. Rev CEFAC. 2014;16(6):2015-28. DOI: http://dx.doi.org/10.1590/1982-0216201416012

11. Scherzer R, Dennis MP, Swan BA, Kavuru MS, Oxman DA. A comparison of usage and outcomes between nurse practitioner and resident-staffed medical ICUs. Crit Care Med. 2017;45(2):132-7. DOI: http://dx.doi.org/10.1097/CCM.0000000000002055

12. Silva RM, Cordeiro AL, Fernandes JD, Silva LS, Teixeira GA. Contribution of a residency specialization program to professional know-how.
Acta paul enferm. 2014;27(4):362-6. DOI: http:// dx.doi.org/10.1590/1982-0194201400060

13. Borochovicius E, TortellaII JCB. Aprendizagem Baseada em Problemas: um método de ensinoaprendizagem e suas práticas educativas. Ensaio: aval pol públ Educ. 2014;22(83):263-94. DOI: http:// dx.doi.org/10.1590/S0104-40362014000200002

14. Setlalentoa M, Ryke E, Strydom H. The influence of binge drinking on social support networks. Social work (Stellenbosch. Online). 2014;50(3):349-70. DOI: http://dx.doi.org/10.15270/50-2-404

15. Polita NB, Tacla MTGM. Rede e apoio social às famílias de crianças com paralisia cerebral. Esc Anna Nery. 2014;18(1):75-81. DOI: http://dx.doi. org/10.10.5935/1414-8145.20140011

16. Spínola AC, Amendoeira J. The Care Process: analysis of Nursing students' conceptions. Rev Enf Ref. 2014 maio/jun;Série IV(2):163-70. DOI: http:// dx.doi.org/10.12707/RIV14006

Recebido: 13 de novembro de 2019

Aprovado: 4 de dezembro de 2019

Publicado: 20 de março de 2020

A Revista Baiana de Enfermagem utiliza a Licença Creative Commons - Atribuição-NãoComercial 4.0 Internacional.

https://creativecommons.org/licenses/by-nc/4.0/

Este artigo é de acesso aberto distribuído sob os termos da Licença Creative Commons (CC BY-NC).

Esta licença permite que outros remixem, adaptem e criem a partir do seu trabalho para fins não comerciais. Embora os novos trabalhos tenham de lhe atribuir o devido crédito e não possam ser usados para fins comerciais, os usuários não têm de licenciar esses trabalhos derivados sob os mesmos termos. 